\title{
KARIŲ ORGANIZMO ATSAKAS ATLIEKANT ŽYGI AUKŠTOS TEMPERATŪROS APLINKOJE
}

\author{
Renaldas Sipavičius ${ }^{1}$, Irina Ramanauskiene $\dot{e}^{2}$, Albertas Skurvydas ${ }^{3}$, \\ Laura Daniusevičiūtė $\dot{e}^{2,3}$, Vitas Linonis ${ }^{2}$, Lina Barsienè $\dot{1}^{1}$ \\ Kauno medicinos universitetas ${ }^{1}$, Kauno technologijos universitetas ${ }^{2}$, \\ Lietuvos kūno kultūros akademija ${ }^{3}$, Kaunas, Lietuva
}

\begin{abstract}
Renaldas Sipavičius. Kauno medicinos universiteto visuomenès sveikatos mokslų doktorantas. Mokslinių tyrimų kryptis — karių nuovargio subjektyvus ir objektyvus ịvertinimas.
\end{abstract}

\section{SANTRAUKA}

Tyrimo tikslas - nustatyti aukštos aplinkos temperatūros poveiki kariu organizmui atliekant specialuji žygì. Buvo tiriami fiziškai aktyvūs (n=12), 19,5 $\pm 1,5$ metu kariai (vyrai). Ju ügis - 181,5 $\pm 4,4 \mathrm{~cm}$, küno mase testavimo metu $-76,0 \pm 7,1 \mathrm{~kg}$. Kariai atrinkti taikant atsitiktinés atrankos metoda. Tyrimo protokolas aptartas ir patvirtintas Kauno regioniniame biomedicininiu tyrimu etikos komitete (protokolo Nr. BE-2-443).

Tyrimas atliktas Ruklos karineje iguloje. Tiriamieji prieš eksperimenta buvo supažindinti su jo eiga. Oro temperatūra viso tyrimo metu pastovi $\left(25-27^{\circ} \mathrm{C}\right)$. Prieš specialuji žygi buvo matuojama oralinè ir rektalinè kūno temperatūra, širdies susitraukimu dažnis, sistolinis ir diastolinis kraujo spaudimas, centrinès nervu sistemos funkcinè būklè. Atlikdami specialuji (20 min) žygi, kariai turèjo ivveikti $2 \mathrm{~km}$ trasq su ivvairiomis kliütimis (lipimais ir nusileidimais $6 \mathrm{~m}$ aukščio sienele, lindimu $500 \mathrm{~m}$ apkasu, nusileidimais virve nuo vienos upès kranto iki kito, pataikymu i taikini). Specialiojo žygio metu kariai 5, 10 ir 15 minutę turejo ìvertinti savo šiluminę jausenq ir šilumini komforta. Iš karto po žygio, praejus 2, 5, 10 ir 30 min po jo buvo matuojamas širdies susitraukimu dažnis, sistolinis ir diastolinis kraujo spaudimas. Oraliné temperatūra išmatuota iš karto po žygio ir praejus 5, 10, 30 min po jo. Rektalinè temperatūra buvo matuojama iš karto po žygio. Centrinès nervu sistemos funkciné būkle registruota praèjus 3 min po žygio.

Vertinant širdies ir kraujagysliu sistemos rodikliu kaitq nustatyta, kad širdies susitraukimu dažnis ir sistolinis kraujo spaudimas, lyginant su ramybès būsena, reikšmingai padidejo $(p<0,05)$. Iki 15 minutès vidutiniai šiluminès jausenos ir komforto vertinimo rodikliai padidejo nuo šiek tiek šilta ir šiek tiek nepatogu iki karšta ir labai nepatogu $(p<0,05)$. Tarp šiu rodikliu nustatytas stiprus koreliacinis ryšys ( $r=0,99 ; p<0,001)$.

Šiuo tyrimu nustatyta, kad atliekant specialuji žygi aukštos temperatūros aplinkoje vertinti širdies ir kraujagysliu sistemos, oralinès ir rektalinès kūno temperatūros, šiluminès jausenos ir šiluminio komforto bei centrinès nervu sistemos funkcinès būklès rodikliai rodo kariu centrinị nuovargị.

Raktažodžiai: kariniai igūižziai, aukšta aplinkos temperatūra, centrinis nuovargis.

\section{IVADAS}

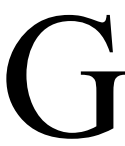
arbinga karininko profesija pasirinkę jaunuoliai visada buvo ir liks valstybès simbolis, nepriklausomos Lietuvos kariuomenès tradicijų tęsejjai ir puoselètojai. Jų profesionalumas, ištvermè ir dora — didžiausias mūsu tautos turtas, valstybès jègos ir išlikimo garantas (Vaičeliūnas, 2002). Ekstremaliomis mūšio sąlygomis kovinio parengtumo lygis gali lemti pergalę, išsaugoti kariu gyvybę ir sveikatą (Endrijaitis, Radžiukynas, 2003). Specialieji karių žygiai vyksta ivvairiomis sąlygomis (esant žemai ar aukštai aplinkos temperatūrai, padidejjus ar sumažejjus atmosferos slègiui), todèl būtina i j jas atsižvelgti. Žmogaus galimybė atlikti fizini darbą tiesiogiai priklauso nuo kūno vidinès temperatūros svyravimo. Padidèjus ašinei kūno temperatūrai iki kritinès ribos (vi- 
dutinio fizinio aktyvumo asmenu $-38,7 \pm 0,2^{\circ} \mathrm{C}$, didelio meistriškumo $-39,2 \pm 0,1^{\circ} \mathrm{C}$ ), žmogaus kūnas perkaista, pasireiškia valingų pastangų nuovargis (Cheung, McLellan, 1998). Padidejus kūno temperatūrai, padažnèja nervinių impulsų perdavimas smegenims, gausiau prakaituojama. Tuo pačiu metu aktyvèja kraujo apykaitos procesai (Armstrong, Marech, 1991).

Literatūroje nuolatos keliama hipotezè, kad pavojingai aukšta vidinè kūno temperatūra padidina nuovargi ir pagreitina išsekimą. Pastaroji tema yra plačiai nagrinèjama, tačiau esminiai mechanizmai nėra iki galo suprasti (Morrison et al., 2004). Raumeniui nuvargus, sutrinka nervo raumens sinapsès veikla, veikimo potencialo sklidimas $\mathrm{T}$ sistema, mažèja $\mathrm{Ca}^{2+}$ išsiskyrimo iš sarkoplazminio tinklo greitis ir kiekis, lěčiau susidaro miozino ir aktino skersiniai tilteliai, todèl mažèja raumenų susitraukimo jẻga, galingumas ir atsipalaidavimo greitis. Griaučiu raumenims nuvargus, lèteja adenozintrifosfato (ATP) hidrolizè ir resintezè (Fitts, 1994), daugèja vandenilio jonų ir neorganinio fosfato (Sahlin et al., 1998), dèl to mažèja aktino ir miozino tilteliu sukibimo jèga ir greitis, miofibriliu jautrumas $\mathrm{Ca}^{2+}$ (Westerblad et al., 2002). Kuri laiką buvo manoma, kad mechanizmas, paaiškinantis neuroraumenini nuovargi, esant aukštai vidinei kūno temperatūrai, galejo susidaryti tiek dèl centrinès, tiek dèl periferinès nervų sistemos pokyčio (Kent-Braun, 1999). M. M. Thomas ir kt. (2006) tyrimu irodè, kad aukšta vidinè kūno temperatūra sumažina neuroraumenini darbinguma, ir tai priklauso nuo centrinès nervu sistemos negaléjimo iki galo aktyvuoti raumens. L. Nybo ir B. Nielsen (2001) nustate, kad atliekant fizinį krūvị aukštos temperatūros aplinkoje vidinè raumenų temperatūra padidèja daugiau nei $3^{\circ} \mathrm{C}$, ir tai gali būti tiesioginè priežastis, dèl ko atsiranda nuovargis centrineje nervų sistemoje. Centrinès nervų sistemos (CNS) siunčiamos komandos lemia raumenu pastangu dydi, judesių dažnio kaitą ir kitus tarpraumeninès koordinacijos ypatumus (Taylor et al., 19996). Todèl CNS darbingumo ir funkcinès būklès pokytis visada matomas iš raumenų veiklos rodikliu (Busso et al., 2002). Ši glaudi CNS ir raumenu funkcijų sąveika yra labai reikšminga atliekant fizinius pratimus įvairiomis aplinkos sąlygomis, todèl ji turi būti vertinama specialiujų žygiu metu.

Taigi tyrimo tikslas - nustatyti aukštos aplinkos temperatūros poveikị karių organizmui atliekant specialuji žygi.

\section{TYRIMO METODIKA IR ORGANIZAVIMAS}

Buvo tiriami fiziškai aktyvūs $(\mathrm{n}=12)$, $19,5 \pm 1,5$ metu kariai (vyrai). Jų ūgis $181,5 \pm 4,4 \mathrm{~cm}$, kūno masè testavimo metu $76,0 \pm 7,1 \mathrm{~kg}$. Kariai atrinkti taikant atsitiktinès atrankos metodą. Tyrimas atliktas laikantis 1975 m. Helsinkio deklaracijoje priimtu principu dèl žmonių eksperimentų etikos. Tyrimo protokolas aptartas ir patvirtintas Kauno regioniniame biomedicininių tyrimų etikos komitete (protokolo $\mathrm{Nr}$. BE-2-443).

Širdies ir kraujagyslių sistemos būsenos matavimas. Specialiojo žygio metu karių širdies susitraukimų dažnis (ŠSD) buvo registruojamas pulso matuokliu „Polar 625 x“ (Suomija) (prieš krūvi, iš karto po jo bei praejjus 2, 5, 10 ir 30 min po krūvio). Sistolinis (SKS) ir diastolinis (DKS) kraujo spaudimas taip pat buvo matuojami prieš krūvị, iš karto po jo, praejus 2, 5, 10 ir 30 min po krūvio naudojant žasto kraujospūdžio matuokli (Microlife BP A80, Šveicarija).

Oralinès temperatūros matavimo metodika. Oralinè temperatūra buvo matuojama silikoninès gumos zondu su termodavikliu (Ellab, Danija). Tiriamasis prieš krūvi, iš karto po jo, praejjus 5,10 ir 30 min po krūvio ịsikišdavo zondą su termodavikliu i burną (matavimo laikas - $10 \mathrm{~s}$ ) (Cheung, Mclellan, 1998). Zondas su termodavikliu po panaudojimo sterilizuojamas autoklave.

Rektalinès temperatūros matavimo metodika. Rektalinè temperatūra buvo matuojama zondu, apvilktu silikonine guma su imontuotu termodavikliu (Ellab, tipas Rectal probe, Danija). Tiriamasis prieš krūvi, iš karto po jo issikišdavo zondą su termodavikliu i i išeinamają angą (matavimo laikas - 10 s) (Proulux et al., 2003). Zondas su termodavikliu po panaudojimo sterilizuojamas autoklave.

Modifikuota šiluminès jausenos ir šiluminio komforto vertinimo metodika. Šiluminè jausena ir šiluminis komfortas buvo matuojamas žygio metu. Kas 5 minutes tiriamieji turejo įvertinti savo šiluminę jauseną (nuo nepakeliamai šalta (0 balų) iki nepakeliamai karšta (10 balų)) ir šilumini komfortą (nuo patogu (1 balas) iki ypatingai nepatogu (5 balai)) (Gagge et al., 1967).

Centrinès nervų sistemos funkcinès būklès vertinimas. Centrinès nervų sistemos funkcinès būklè buvo matuojama karių specialiojo žygio metu. Reakcijos laikas matuojamas reakciometru (judesių dažnio matuokliu $R A-1$ ), skirtu psicho- 
motorinès reakcijos greičiui ir centrinès nervu sistemos funkcinei būklei vertinti. Eksperimento metu prieš krūvị ir po jo buvo matuojamas dešinès rankos reakcijos laikas nuo lemputès užsidegimo iki klavišo paspaudimo momento (ms). Visi duomenys perduodami ir apdorojami kompiuteriu. Tiriamasis atliko 15 bandymų abiem rankom.

Tyrimo eiga. Tyrimas atliktas Ruklos karineje iguloje. Tiriamieji prieš eksperimentą buvo supažindinti su jo eiga. Oro temperatūra viso tyrimo metu buvo pastovi $\left(25-27^{\circ} \mathrm{C}\right)$. Prieš specialuji žygi išmatuota oralinè, rektalinè kūno temperatūra, širdies susitraukimų dažnis, sistolinis ir diastolinis kraujo spaudimas, centrinès nervų sistemos funkcinè būklè. Atlikdami specialuji (20 min) žygi, kariai turèjo ịveikti $2 \mathrm{~km}$ trasą su ịvairiomis kliūtimis (lipimu ir nusileidimu $6 \mathrm{~m}$ aukščio sienele, lindimu $500 \mathrm{~m}$ apkasu, nusileidimu virve nuo vienos upés kranto iki kito, pataikymu i taikini). Specialiojo žygio metu kariai 5, 10 ir 15 minute turejjo įvertinti savo šiluminę jauseną ir šilumini komfortą. Iš karto po žygio bei praejjus 2, 5, 10 ir 30 min po jo buvo matuojamas širdies susitraukimų dažnis, sistolinis ir diastolinis kraujo spaudi- mas. Oralinè temperatūra buvo matuojama iš karto po žygio ir praejjus 5, 10, 30 min po jo. Rektalinè temperatūra išmatuota iš karto po žygio. Centrinès nervų sistemos funkcinè būklè buvo registruojama praejjus 3 min po žygio.

Statistiniai skaičiavimai. Apdorojant tyrimų duomenis, apskaičiuotas aritmetinis vidurkis, standartinis nuokrypis. Skirtumo tarp aritmetiniu vidurkiu reikšmingumas buvo nustatomas pagal dvipusi nepriklausomu imčių Studento t kriterijų. Aritmetinių vidurkių skirtumo reikšmingumo lygmuo buvo laikomas svarbiu, kai paklaida mažesnè nei $5 \%(\mathrm{p}<0,05)$. Skaičiavimai atlikti naudojantis statistiniais Microsoft ${ }^{\circledR}$ Excel 2003 ir SPSS paketais.

\section{REZULTATAI}

Vertinant širdies ir kraujagyslių sistemos kaitą nustatyta, kad širdies susitraukimų dažnis ( ̌SSD) ir sistolinis kraujo (ŠKS) spaudimas, lyginant su ramybès būsena, reikšmingai padidejo $(\mathrm{p}<0,05)$, tuo tarpu registruojant diastolini kraujo spaudimą (DKS) reikšmingo skirtumo neaptikta $(\mathrm{p}>0,05)$ (1 pav.).
1 pav. Širdies ir kraujagyslių sistemos rodiklių kaita specialiojo žygio metu

\section{Pastaba.}

- p $<0,05$, širdies susitraukimų dažnio pokytis, lyginant su reikšme prieš krūvị;

$\dagger-\mathrm{p}<0,05$, sistolinio kraujo spaudimo pokytis, lyginant su reikšme prieš krūvị;

$£-\mathrm{p}<0,05$ diastolinio kraujo spaudimo pokytis, lyginant su reikšme prieš krūvị.

2 pav. Subjektyvios šiluminės jausenos ir šiluminio komforto vertinimas specialiojo kariūnų žygio metu

Pastaba.

* — $\mathrm{p}<0,05$, šiluminès jausenos pokytis; $\dagger-p<0,05$, šiluminio komforto pokytis.

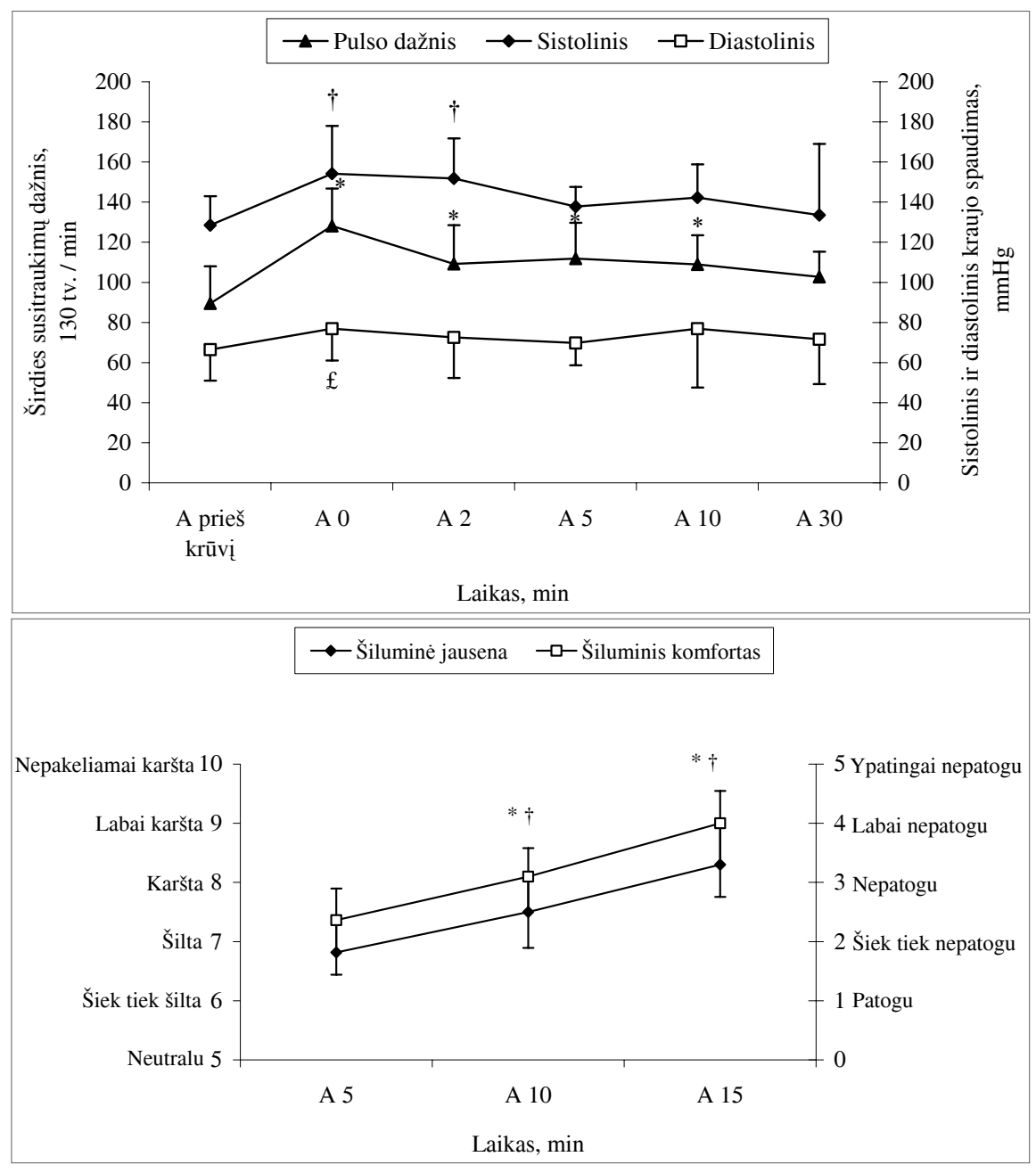






Žygio metu oralinè temperatūra padidejo nuo $36,1 \pm 0,5$ iki $36,9 \pm 0,8^{\circ} \mathrm{C}(\mathrm{p}<0,001)$, rektalinè nuo $36,87 \pm 0,28$ iki $39,92 \pm 0,31^{\circ} \mathrm{C}(\mathrm{p}<0,001)$.

Iki 15 minutès vidutiniai šiluminès jausenos ir komforto vertinimo rodikliai padidejjo nuo šiek tiek šilta ir šiek tiek nepatogu iki karšta ir labai nepatogu (2 pav.) $(\mathrm{p}<0,05)$. Tarp šių rodiklių nustatytas stiprus koreliacinis ryšys $(r=0,99$; $\mathrm{p}<0,001)$.

Vertinant centrinès nervų sistemos funkcinę būklę nustatyta, kad maksimalus reakcijos laikas po krūvio (230,9 ms), palyginti su pradine reikšme $(209,3 \mathrm{~ms})$, reikšmingai padidèjo $(\mathrm{p}<0,05)$. Vidutinis ir minimalus reakcijos laikas reikšmingai nepakito $(\mathrm{p}>0,05)(3$ pav. $)$.

\section{REZULTATU APTARIMAS}

Šiuo tyrimu nustatyta, kad atliekant specialuji žygi aukštos temperatūros aplinkoje vertinti širdies ir kraujagyslių sistemos, oralinès ir rektalinès kūno temperatūros, šiluminès jausenos ir šiluminio komforto, centrinès nervų sistemos funkcinès būklès rodikliai rodo karių centrini nuovargi.

Aukšta aplinkos temperatūra ir padidejjusi vidinè organizmo temperatūra pagreitina nuovargio atsiradima, atliekant didelio intensyvumo pratimus (Gonzalez-Alonso et al., 1999). Aukšta vidinè kūno temperatūra padidina fiziologinę kūno ịtampą, kurios metu gali smarkiai sumažèti fizinis darbingumas, vedantis prie išsekimo, perkaitimo, traumos ir netgi mirties (Cheung, Sleivert, 2004). Padidejjus kūno temperatūrai, padažnėja nervinių impulsų perdavimas smegenims, gausiau prakaituojama. Tuo pačiu metu aktyveja kraujo apykaitos procesai (Armstrong, Marech, 1991). Kai raumenu temperatūra padidejusi, intensyvaus krūvio metu ATP, kreatinfosfato (KP) kiekio mažèjimas ir ju skilimo produktų kaupimasis yra didesnis, nei esant normaliai raumenu temperatūrai. Pakilus raumenų temperatūrai, paspartèja ATP hidrolizė (Ball et al., 1999) ir anaerobiné glikolizè (Febbraio, 2000). Taigi aukšta vidinè kūno temperatūra padidina ATP panaudojimą krūvio metu. Greičiau prasideda glikogenolizès, glikolizès procesai (Febbraio, 2000).

L. Nybo ir B. Nielsen (2001), irodè, kad karšto oro sąlygomis atliekant fizinius pratimus (kai ašinè temperatūra siekia daugiau nei $39^{\circ} \mathrm{C}$ ) atsiranda nuovargis, kuris tiesiogiai veikia centrinę nervų sistemą. Vidinès temperatūros pakèlimas daugiau kaip $3^{\circ} \mathrm{C}$ yra savotiškas slenkstis, kuri peržengus dèl sutrikusios termoreguliacijos ribojamos fizinès galios (Kaciuba-Uscilko et al., 1992). Šie autoriai taip pat teigia, kad odos paviršinès temperatūros, širdies ir kraujagysliu sistemos, subjektyvaus fiziologinio pojūčio ir komforto rodiklių kaita nèra pagrindiniai veiksniai, lemiantys žmogaus organizmo fizinių galių sukeliamą nuovargi. Vis dèlto mes nustatėme, kad iki 15 minutès vidutiniai šiluminès jausenos ir komforto vertinimo rodikliai padidejo nuo šiek tiek šilta ir šiek tiek nepatogu iki karšta ir labai nepatogu $(p<0.05)$. Tarp šių rodiklių nustatytas stiprus koreliacinis ryšys $(r=0,99$; $\mathrm{p}<0,001)$.

Atlikto tyrimo duomenys sutampa su P. J. Sowood ir E. M. O'Connor (1994) gautaisiais. Šie mokslininkai atliko eksperimentą, kurio metu tyrè karius skrydžio metu, esant aukštai aplinkos temperatūrai. Buvo nustatyta padidejusi tiriamujų ašinè ir odos temperatūra, širdies susitraukimu dažnis bei šiluminio komforto rodikliai, ir tai rodo karių centrini nuovargi. Atliekant žygi aukštos temperatūros aplinkoje, temperatūrinè homeostazè didina parkaitavimą ir širdies kraujagysliu sistemos darbą (Armstrong, 2000). S. S. Radakovic ir kt. (2007) atliko eksperimentą, kurio metu tyre karių organizmo fiziologini atsaką $\mathfrak{i}$ aukštą aplin- 
kos temperatūrą. Mokslininkai nustatè, kad esant $29^{\circ} \mathrm{C}$ aplinkos temperatūrai padidèjo karių širdies susitraukimų dažnis, tačiau po 10 dienų aklimatizacijos laikotarpio statistinio skirtumo jau nebuvo (Radakovic et al., 2007). Atlikto tyrimo duomenys parodè, kad specialiojo žygio metu aukštos temperatūros sąlygomis padidèjo kariu širdies susitraukimų dažnis, sistolinis kraujo spaudimas, oralinè ir rektalinè kūno temperatūros, šiluminès jausenos ir šiluminio komforto bei centrinès nervų sistemos funkcinès būklès rodikliai, kurie rodo karių centrini nuovargi.

\section{IŠVADOS}

Specialiojo žygio metu (esant aukštai aplinkos temperatūrai) vertinti širdies ir kraujagyslių sistemos, oralinès ir rektalinès kūno temperatūros, šiluminès jausenos ir šiluminio komforto rodikliai rodo karių centrini nuovargi.

\section{LITERATŪRA}

Armstrong, L. E., Marech, C. M. (1991). The induction and decay of heat acclimatisation in trained athletes. Sports Medicine, 12, 302-312.

Armstrong, L. E. (2000). Performing in extreme environments. Human Kinetics. P. 15-63.

Ball, D., Burrows, C., Sargeant, A. J. (1999). Human power output during repeated sprint cycle exercise: The influence of thermal stress. European Journal of Applied Physiology, 79, 360-366.

Busso, T., Benoit, H., Bonnefoy, R., Feasson, L., Lacour, J. R. (2002). Effects of training frequency on the dynamics of performance response to a single training bout. Journal of Applied Physiology, 92 (2), 572-580.

Cheung, S. S., Mclellan, T. M. (1998). Comparison of short-term aerobic training and high aerobic power on tolerance to uncompensable heat stress. Aviation, Space, and Environmental Medicine, 70 (7), 637-643.

Cheung, S. S., Sleivert, G. G. (2004). Multiple triggers for hyperthermia fatigue and exhaustion. Journal of Exercise and Sport Science Reviews, 45, 100-106.

Endrijaitis, R., Radžiukynas, D. (2003). Generolo Jono Žemaičio Lietuvos karo akademijos pirmo kurso karių fizinio rengimo ypatumai. Ugdymas. Küno kultūra. Sportas, 5 (56), $8-13$.

Febbraio, M. A. (2000). Does muscle function and metabolism affect exercise perfomance in the heat? Exercise and Sport Science Reviews, 28, 171-176.

Fitts, R. H. (1994). Cellular mechanisms of muscle fatigue. Physiological Review, 7, 49-95.

Gagge, A. P, Stolwijk, J. A, Hardy, J. D. (1967). Comfort and thermal sensations and associated physiological responses at various ambient temperatures. Journal of Environmental Research, 1, 1-20.

Gonzalez-Alonso, J., Teller, C., Andersen, S. L. et al. (1999). Influence of body temperature on the development of fatigue during prolonged exercise in the heat. Journal of Applied Physiology, 86, 1032-1039.

Kaciuba-Uscilko, H., Kruk, B., Szejczewska, M. et al. (1992). Methabolic, body temperature and hormonal responses to related periods of prolonged cycle ergometer exercise in men. European Journal of Applied Physiology, $64,26-31$.
Kent-Braun, J. A. (1999). Specific strength and voluntary muscle activation in young and elderly women and men. Journal of Applied Physiology, 87, 22-29.

Morrison, S. A., Sleivert, G. G., Cheung, S. S. (2004). Passive hyperthermia reduces voluntary activation and isometric force production. European Journal of Applied Physiology, 91, 729-736.

Nybo, L., Nielsen, B. (2001). Hyperthermia and central fatigue during prolonged exercise in humans. Journal of Applied Physiology, 91, 1055-1060.

Proulux, C. I., Ducharme, M. B., Kenny, G. P. (2003). Effect of water temperature on cooling efficiency during Hyperthermia in humans. Journal of Applied Physiology, 94, 1317-1325

Radakovic, S. S., Maric, J., Surbatovic, M. et al. (2007). Effects of acclimation on cognitive performance in soldiers during exertional heat stress. Military Medicine, 172 (2), 133-136.

Sahlin, K., Tonkonogi, M., Söderlund, K. (1998). Energy supply and muscle fatigue in humans. Acta Physiologica Scandinavica, 162, 261-266.

Sowood, P. J., O'Connor, E. M. (1994). Thermal strain and $\mathrm{G}$ protection associated with wearing an enhanced anti-G protection system in a warm climate. Aviation, Space, and Environmental Medicine, 65 (11), 992-998.

Taylor, J. L., Butler, J. E., Allen, G. M., Gandevia, S. C. (1996). Changes in motor cortical excitability during human muscle fatique. Journal of Physiology, 15, 490, $519-528$.

Thomas, M. M., Cheung, S. S., Elder, G. C., Sleivert, G. G. (2006). Voluntary muscle activation is impaired by core temperature rather than local muscle temperature. Journal of Applied Physiology, 100, 1361-1369.

Vaičeliūnas, A. (2002). Esame jauniausia Lietuvos aukštoji mokykla. Krašto apsauga, 12 (15), 2-3.

Westerblad, H., Allen, D. G, Lannergren, J. (2002). Muscle fatigue: Lactic acid or inorganic phosphate the major cause? News in Physiological Sciences, 17, 17-21. 


\title{
THE EFFECT OF WARM ENVIRONMENT ON THE HUMAN ORGANISM PERFORMING MILITARY SKILLS
}

\author{
Renaldas Sipavičius ${ }^{1}$, Irina Ramanauskiené ${ }^{2}$, Albertas Skurvydas ${ }^{3}$, \\ Laura Daniusevičiūté $\dot{e}^{2,3}$, Vitas Linonis ${ }^{2}$, Lina Barsiené ${ }^{1}$ \\ Kaunas University of Medicine ${ }^{1}$, Kaunas University of Technology ${ }^{2}$, \\ Lithuanian Academy of Physical Education ${ }^{3}$, Kaunas, Lithuania
}

\begin{abstract}
The aim of the study was to establish the effect of warm environment performing military skills. The participants of the study were 12 healthy males, aged $19.5 \pm 1.5$ years; height $-181.5 \pm 4.4$; body mass $76.0 \pm 7.1$. They were physically active, non-smokers and free of any clinically significant diseases that could affect their exercise performance. The protocols of the research had been discussed and approved by Kaunas Regional Ethics Committee of Biomedical Research (Protocol No BE-2-443).

The research was carried out in Rukla Military Base. The subjects were acquainted with the aims of the study, its procedure and the possible discomfort. The temperature of the environment was $25-27^{\circ} \mathrm{C}$. Before the special work, the oral, rectal temperatures, the cardiac and cardiovascular systems, the thermal sensation and the thermal comfort, as well as the state of central nerve systems of the soldiers were evaluated. The military performed the special work of $2 \mathrm{~km}(20 \mathrm{~min})$. The soldiers had to establish their thermal sensation and thermal comfort at the $5^{\text {th }}, 10^{\text {th }}$ and $15^{\text {th }}$ min of the special work. The oral temperatures of the military were measured at the end of the special work as well as 2, 5, 10 and 20 min after it. The rectal temperatures were measured at the end of the special work. Similarly, the cardiac and the cardiovascular systems of the soldiers were evaluated as soon as the special work was finished as well as 5,10 and $30 \mathrm{~min}$. after it. The state of their central nerve systems was established 3 min after the special work.

After analyzing the thermal sensation, we found that during the special work the subjects experienced a thermal sensation of heat, their thermal comfort evaluation during the special work showed that it was very uncomfortable $(\mathrm{p}<0.05)$. The assessment of the cardiac and cardiovascular system data showed an increase in results.

The main conclusion. The oral and rectal temperatures, the cardiac and cardiovascular system, the thermal sensation and thermal comfort, the state of central nerve system increased central fatigue of soldiers in warm environment.
\end{abstract}

Keywords: military skills, warm environment, central fatigue.

Gauta 2008 m. gegužès $1 \mathrm{~d}$.

Received on May 1, 2008

Priimta $2008 \mathrm{~m}$. birželio $18 \mathrm{~d}$.

Renaldas Sipavičius

Accepted on June 18, 2008

Kauno medicinos universitetas

(Kaunas University of Medicine)

A. Mickevičiaus g. 9, LT-44307 Kaunas

Lietuva (Lithuania)

Tel +37037327201

E-mail renaldas@medita.lt 